\title{
Third-degree burns caused by ignition of chlorhexidine: A case report and systematic review of the literature
}

\author{
Anthony $\mathrm{Vo}^{1}$, Omar Bengezi MBBS MD FRCSC ${ }^{2}$
}

\begin{abstract}
A Vo, O Bengezi. Third-degree burns caused by ignition of chlorhexidine: A case report and systematic review of the literature. Plast Surg 2014;22(4):264-266.
\end{abstract}

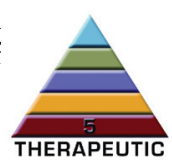

Ignition of chlorhexidine by an electrocautery unit is rare but can have devastating consequences for the patient and the surgeon. A case involving a 77-year-old man who underwent removal of an indwelling artificial urethral sphincter is presented. The chlorhexidine was ignited when the urologist activated the electrocautery unit, causing third-degree burns to the patient. A plastic surgeon treated the burns with surgical debridement and split-thickness skin grafting. A systematic review of the literature was performed with best practice recommendations. To the authors' knowledge, the present case is the ninth such case reported.

Key Words: Burn; Chlorhexidine; Prevention; Surgical fire

\section{Des brûlures au troisième degré causées par l'ignition de la chlorhexidine : rapport de cas et analyse bibliographique}

Il est rare que la chlorhexidine s'enflamme à cause d'un dispositif d'électrocautérisation, mais un tel incident peut avoir des conséquences dévastatrices, à la fois pour le patient et pour le chirurgien. Les auteurs présentent le cas d'un homme de 77 ans qui s'est fait enlever un sphincter urétral artificiel à demeure. La chlorhexidine s'est enflammée lorsque l'urologue a activé le dispositif d'électrocautérisation, ce qui a brûlé le patient au troisième degré. Un chirurgien plasticien a traité les brûlures par débridement chirurgical et greffe dermo-épidermique. Les auteurs ont effectué une analyse bibliographique et extrait les recommandations exemplaires. En autant qu'ils le sachent, le présent cas est le neuvième du genre à être déclaré.
Surgical fires in the operating room are rare, but can have devastat$\checkmark$ ing consequences for the patient and the surgeon. The published literature indicates an incidence of approximately 20 to 200 each year in United States (1). Although the majority of surgical fires cause morbidity, mortality can occur (2). For surgeons, it is a source of litigation and, in a recent review, $100 \%$ of incidences have resulted in lawsuits (3); therefore, prevention is important.

The surgical fire triangle is a useful paradigm to understand the three elements necessary to initiate a fire (Figure 1). The three elements are an oxidizer (supplemental oxygen), a fuel and an ignition source. In the operating room, all three are in ample supply (4). The fuel is most often the alcohol-based preparation solution used to disinfect the patient (5). The most common source of ignition is the electrocautery unit, which is used in $85 \%$ of surgeries and responsible for initiating $70 \%$ of surgical fires. In experimental studies, electrocautery units have been shown to easily ignite all alcohol-based preparation solutions even if the solutions contain as little as 20\% alcohol (5).

Chlorhexidine provides broad-spectrum bacteriostatic and bacteriocidal activity (6). It has a rapid onset and appears to be more resistant to contamination than many other antiseptic agents, making it the agent of choice for surgical scrub in several studies (7). Although chlorhexidine is less flammable than many other alcohol-based antiseptic agents, surgical fires may still occur. There are very few case reports of burns caused by the ignition of chlorhexidine by an electrocautery unit. We present a case report and a systematic review with best-practice recommendations.

\section{CASE PRESENTATION}

A 77-year-old man presented to his urologist with worsening obstructive voiding symptoms due to a malfunctioning indwelling artificial urethral sphincter and urethral stricture secondary to radiation. His medical history included type 2 diabetes mellitus, hypertension, hiatus hernia and hyperlipidemia. Previous surgeries included fundoplication, radical prostatectomy for stage $\mathrm{T} 3$ prostate cancer and insertion of the



Figure 1) The surgical fire triangle depicting the three elements necessary for a fire

artificial sphincter. The urologist elected removal of his artificial sphincter to improve his voiding symptoms.

Under general anesthetic, the patient was prepped with chlorhexidine (2\% chlorhexidine gluconate in $70 \%$ isopropyl alcohol) and draped in the supine position. The bulb, reservoir and pump were removed through a suprapubic incision. The incision was closed and the patient was again prepped with chlorhexidine and draped in the lithotomy position. An incision was made in the perineum overlying the sphincter cuff; however, when the electrocautery unit was activated, the drapes - wet with chlorhexidine - were ignited. It was quickly extinguished with sterile saline. At this point, the procedure was immediately aborted, the incision was closed and plastic surgery was consulted to assess the burns, while the patient was under general anesthetic.

Assessment by the plastic surgeon revealed first-degree burns involving the symphysis pubis area, scrotum, the anterior surface of the proximal third of the penis and the anterior upper thighs. Second-degree burns were located in the perineum, measuring $5 \mathrm{~cm}$ 
$\times 5 \mathrm{~cm}$. Further examination revealed the presence of leather-like triangular areas involving the skin in the right and left gluteal areas overlying the ischial tuberosities, measuring $7 \mathrm{~cm} \times 4 \mathrm{~cm} \times 7 \mathrm{~cm}$ on each side, consistent with third-degree burns (Figure 2). No circumferential burns were noted.

After the initial assessment, the plastic surgeon applied topical Flamazine (Smith \& Nephew, USA) (silver sulfadiazine), salinesoaked gauze, abdominal pads and started the patient on antibiotics. The plastic surgeon then admitted the patient to hospital to reassess the burns and to discuss further management with the patient.

Four days later, the patient was brought to the operating room for excision of his third-degree burns and closure with split-thickness skin graft obtained from the lateral aspect of the left thigh.

Ten days following the injury, the incision and graft were healing well, and the patient was discharged from the hospital with analgesic and antibiotic medications. Arrangements were made with the plastic surgeon, urologist and home care. At six weeks, a hypertrophic scar was noted in the right gluteal area and was treated with cortisone injections. The remainder of his recovery was uneventful. A lawsuit was later filed against the urologist.

\section{METHODS}

A systematic review of the literature was performed to identify reported cases of burns caused by the ignition of chlorhexidine by an electrocautery unit. Databases searched included Embase (searched 1947 to May 2014), MEDLINE (searched 1946 to May 2014), Healthstar (searched 1966 to April 2014) and Cochrane (searched 2005 to April 2014). Search terms included "chlorhexidine," "surgical procedure," "surgery," "operating," "burn" and "fire." One reviewer reviewed titles and abstracts to identify potentially relevant studies. Studies were included if ignition of chlorhexidine involved human patients, ignition was caused by an electrocautery unit and an English abstract was available. References of the search results were reviewed to acquire outstanding articles not found in the initial literature search. Best-practice recommendations were then created based on previous case reports.

\section{RESULTS}

The initial search strategy identified 102 potential articles. Following the inclusion criteria and a review of the references, a total of six articles were included in the present systematic review $(5,8-12)$. The literature review demonstrated that surgical fires caused by the electrocautery unit are rare in the operating room. The published literature is even more scarce due to poor reporting protocols and liability concerns. A total of eight cases caused by the ignition of modern chlorhexidine preparation solution by an electrocautery unit have been published (Table 1). To the authors' knowledge, the present case is the ninth such case. All cases attribute the cause of the fire to either the lack of sufficient time to allow chlorhexidine to dry or to the liberal application of the solution, causing retention in dependent areas, or in surgical drapes and towels.

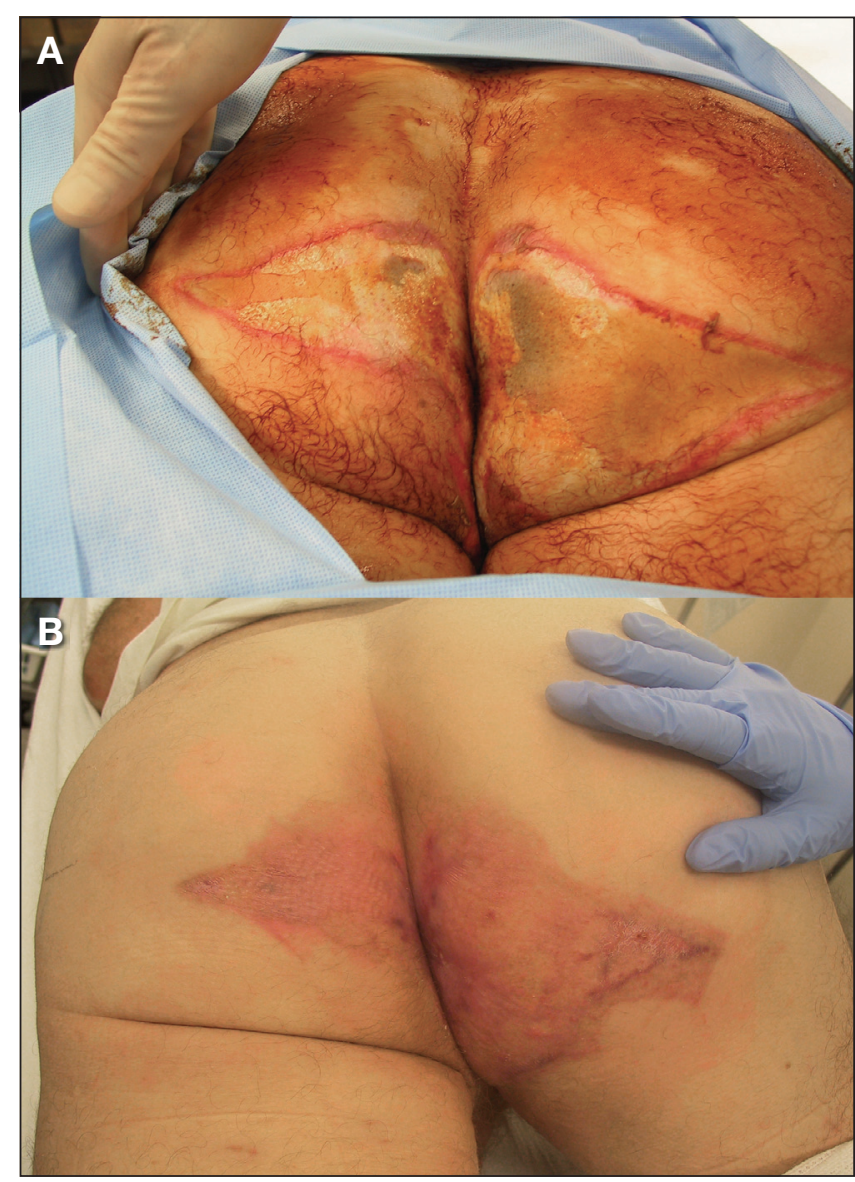

Figure 2) A Third-degree burns involving the gluteal areas four days after a surgical fire caused by the ignition of chlorhexidine by an electrocautery unit. B Ninety days after surgical debridement and split-thickness skin grafting

\section{BEST-PRACTICE RECOMMENDATIONS}

1. Before the application of chlorhexidine, the surgeon should ensure that no absorptive materials are present or should remove them after the patient has been prepped.

2. A sufficient amount of visibly dyed chlorhexidine should only be used to prevent pooling. Application of chlorhexidine-soaked sponges should be avoided.

3. Ensure complete evaporation of chlorhexidine by allowing a longer drying time than what is recommended by the manufacturer $(2 \mathrm{~min}$ to $3 \mathrm{~min}$ ); $5 \mathrm{~min}$ is preferred (10).

\section{TABLE 1}

\section{Cases of burns caused by the ignition of chlorhexidine by an electrocautery unit}

\begin{tabular}{|c|c|c|c|}
\hline Author (reference), year & Age, years & Surgical procedure & Severity of burn \\
\hline Briscoe et al (5), 1976 & Not reported & Abdominal incision & Not reported \\
\hline \multirow[t]{2}{*}{ Fong et al (8), 2000} & 32 & Incision and drainage of axillary abscess & Third-degree burns over the axilla \\
\hline & - & Laser hemorrhoidectomy & First-degree burns to perineum \\
\hline \multirow[t]{2}{*}{$\begin{array}{l}\text { Bonde and Alsbjorn (9), } \\
2002\end{array}$} & 29 & Orchiectomy and biopsy of testes & $\begin{array}{l}\text { Second-degree burns to three areas of the genitofemoral } \\
\text { region }\end{array}$ \\
\hline & 41 & Closure of perianal fistula & $\begin{array}{l}\text { Second-degree burns to vulva, perineum and perianal } \\
\text { regions. Third-degree burns to buttocks ( } 1 \% \text { to } 2 \% \text { of TBSA) }\end{array}$ \\
\hline Tooher et al (10), 2004 & 17 & Urgent lower Caesarean section & $12 \%$ to $16 \%$ third-degree burns to inner thighs and both flanks \\
\hline Uetake et al (11), 2007 & 80 & Ascending colectomy & $\begin{array}{l}\text { Second-degree burns ( } 2 \% \text { of TBSA). Third-degree burns ( } 3 \% \\
\text { of TBSA) to right thorax, lower abdomen and femoral region }\end{array}$ \\
\hline Hoshjima et al (12), 2010 & 29 & Laparotomy for acute abodmen & $\begin{array}{l}\text { Second- to third-degree burns from right thoracic region to } \\
\text { buttocks }\end{array}$ \\
\hline
\end{tabular}


4. Residual chlorhexidine should be dried with a surgical towel.

5. Surgical drapes should only be applied once chlorhexidine has completely evaporated. Adhesive drapes should be used and arranged so that residual chlorhexidine vapour is directed away from the surgical field.

6. The electrocautery unit should be used with the lowest possible setting and should be placed in its quiver when it is not being used.

\section{CONCLUSION}

The present review demonstrates the importance of preventing surgical fires. It is important to be aware that chlorhexidine can be ignited by an electrocautery unit. Best-practice recommendations should be followed before each procedure to prevent this rare but devastating event.

DISCLOSURES: The authors have no financial disclosures or conflicts of interest to declare.

\section{REFERENCES}

1. Abdulrasheed I, Lawal A, Eneye A. Surgical fires An ongoing intra-operative challenge. Arch Int Surg 2013;3:1-5.

2. Podnos YD, Williams RA. Fires in the operating room. Bull Am Coll Surg 1997;82

3. Haith LR, Santavasi W, Shapiro TK, et al. Burn center management of operating room fire injuries. J Burn Care Res 2012;33:649-53.

4. ERCI Institute. The patient is on fire! A surgical fires primer. Guidance 1992;21:19-34.

5. Briscoe CE, Hill DW, Payne JP. Inflammable antiseptics and theatre fires. Br J Surg 1976;63:981-3.

6. Nouri K. Complications in Dermatologic Surgery. Philadelphia: Elsevier 2008:53.

7. Roenigk RK, Roenigk HH. Roenigk \& Roenigk's Dermatologic Surgery: Principles and Practice. New York: Marcel Dekker, 1996:3.

8. Fong E, Tan W, Chye L. Diathermy and alcohol skin preparations a potential disastrous mix. Burns 2000;26:673-5.

9. Bonde CT, Alsbjorn BF. Intraoperative burns. An unforeseen danger? Ugeskr Laeger 2002;165:645.

10. Tooher R, Maddern G, Simpson J. Surgical fires and alcohol-based skin preparations. ANZJ Surg 2004;74:382-5.

11. Uetake A, Nakaigawa Y, Koho Y, Yamada M, Ishii R. Fire caused by a spark of electric scalpel igniting alcoholic antiseptic containing chlorhexidine. Masui 2007;56:718-9.

12. Hoshjima H, Takeuchi R, Sato E, Kikuchi H. Accidental skin burns by fire of an antiseptic agent ignition by the spark of electric cautery. Japanese J Anesthesiol 2010;59:1138-40. 